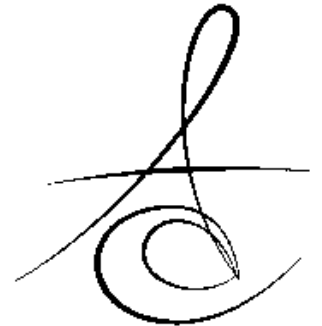

Makale Kodu/Article code: 1747

Makale Gönderilme tarihi: 20.06.2014

Kabul Tarihi: 18.11 .2014

\section{FİBERLE GÜÇLENDİRMENİN NANOFİL KOMPOZİTíN EĞME DİRENCİNE ETKİSİNİN İNCELENMESİ}

\section{EFFECT OF FIBER REINFORCEMENT ON THE FLEXURE STRENGTH OF NANOFILLED-RESIN COMPOSITE}

\author{
Dr. Ümit CANDAN
}

Prof.Dr. Nesrin ERONAT

\section{ÖZET}

Amaç: $\mathrm{Bu}$ in vitro çalışmanın amacl; fiberle güçlendirmenin, nanofil kompozit materyalinin eğme direncine etkisinin araştırılmasıdır.

Materyal ve Metod: Eğme direnci testi için ISO 4049 standartlarına uygun hazırlanan standart bir metal kalıp $(2 \times 2 \times 25 \mathrm{~mm})$ kullanılarak 60 örnek hazırlandı. Örnekler dört çalışma grubuna ayrıldı (n:15). Akışkan Kompozit (Filtek Flow)+Nanofil Kompozit (Filtek Supreme) (Grup I), Nanofil Kompozit (Kontrol) (Grup II), Akışkan Kompozit+Örgü Cam Fiber (EverStick Net)+Nanofil Kompozit (Grup III), Örgü Cam Fiber+Nanofil Kompozit (Grup IV). Örnekler 24 saat $37^{\circ} \mathrm{C}$ de distile suda bekletildi. Daha sonra Universal Test cihazı ile üç nokta eğilme testine tabi tutuldu. Veriler istatistiksel olarak Kruskall Vallis ve Mann Whitney $U$ testi kullanılarak analiz edildi. Her gruba ait üç örnek, taramalı elektron mikroskobunda (SEM) incelendi.

Bulgular: Ortalama eğme direnci değerleri ve standart sapmaları Grup I, II, III ve IV de sırasıyla $93.6 \pm 4,85.5 \pm 6,107 \pm 9$ ve $101 \pm 5$ bulundu. Diğer gruplarla karşılaştırıldığında kontrol grubunun (Gr II) en düşük değere sahip olduğu belirlenirken en yüksek eğme direncinin akışkan kompozit ile beraber fiber uygulanan nanofil kompozit grubunda olduğu gözlendi $(p<0.05)$. Kontrol grubu ile diğer gruplar arasında eğme direnci değerlerinin anlamlı bir farklılık gösterdiği belirlendi $(p<0.05)$. Örnekler SEM ile incelendiğinde, fiber ile güçlendirilmiş gruplarda (GR III ve IV) meydana gelen kırılmanın gerilim bölgesine yerleştirilen fiberle sınırlı kaldığı saptandı.

Sonuç: Bu in vitro çalışmanın sınırları içinde cam fiberle güçlendirmenin, nanofil kompozitin eğme direncini arttırdığı sonucuna varıldı. Örneklerde kırılmanın, gerilim bölgesinde fiberle sınırlı kaldığı; cam fiberin kırık stoperi olarak işlev yaptığı sonucuna varıldı.

Anahtar kelimeler: Kompozit rezin, fiberle güçlendirme, eğme direnci, taramalı elektron mikroskobu (SEM),

\section{ABSTRACT}

Aim: The purpose of this in vitro study was to investigate the effect of woven glass fiber layering on flexural strength of nanofil composite resin.

Material and Method: Sixty specimens were prepared standard metallic mold $(25 \times 2 \times 2 \mathrm{~mm})$ prepared according to ISO 4049 for flexural strength. The specimens were divided into four groups ( $n: 15)$ as follows; Flowable (Filtek Flow) + nanofil composite (Filtek Supreme) (Gr I), nanofil composite (Gr II), Flowable +woven glass fiber (EverStick Net) + nanofil composite (Gr III), woven glass fiber + nanofil composite ( $\mathrm{Gr}$ IV). The specimens were stored in distilled water at $37^{\circ} \mathrm{C}$ for 24 hour, thenevaluated with three-point bending test using Universal Testing Machine. Data were analysed using Kruskall Wallis and Mann Whitney $U$ tests. Three samples from each group were examined by SEM.

Result:The mean flexural strength values of the groups I, II, III and IV were 93.6 $\pm 4,85.5 \pm 6,107 \pm 9$ and $101 \pm 5$ respectively. Glass fiber-reinforced nanofil composite applied with flowable composite (Gr III) exhibited higher flexural strength values in comparison to the other groups ( $p<0.05$ While control group ( $\mathrm{Gr}$ II) exhibited the lowest). Significant differences were found between flexural strength of control and the other groups $(p<0.05)$. In SEM evaluation, it was detected that in fiber-reinforced groups (Groups III and IV) fractured area was limited by the fiber in the stressed region.

Conclusion: Within the limitations of this in vitro study it is concluded that glass fiber reinforcement improves the flexural strength of the nanofill composite. In SEM evaluation after fracturing, glassfiber reinforcement prevented crack propagation.

Key Words: Composite resin, fiberreinforcement, flexural strength, scanning electron microscope

*İzmir Eğitim Diş Hastanes

**Ege Üniversitesi Diş Hekimliği Fakültesi Pedodonti Anabilim Dalı

***Eqe Üniversitesi Dis Hekimliăi Fakültesi Restoratif Tedavi Anabilim Dalı 


\section{GİRİ̧̧}

Önceleri sadece ön dişlerde kullanılan rezin kompozitler, estetik beklentilerinin artması ve materyallerdeki gelişmeler sonucu arka dişlerde de yaygın olarak kullanılmaya başlanmıştır. ${ }^{1,2} \mathrm{Bu}$ nedenle estetik özellikleri yanında çiğneme kuvvetlerine ve aşınmaya dayanıklı kompozit rezinler üzerinde çalışmalar yoğun bir şekilde devam etmektedir. ${ }^{2,3}$ Bu amaca yönelik olarak 2002 yılında nanofil kompozitler (Filtek Supreme, 3M ESPE) üretilmiştir. ${ }^{2-5}$

Mikrofil kompozitin estetiği ve hibrit kompozitin dayanıklılı̆ı gibi olumlu özelliklerin biraraya getirildiği nanofil kompozitler; nanodoldurucu ve nanodoldurucuların gevşek bağlarla birleşiminden oluşan nanoöbeklerden (nanocluster) oluşur. ${ }^{4,5}$ Boyutları küçük olan nanodoldurucuların, her boşluğu doldurmaları, doldurucu oranının artmasına neden olarak rezin materyalin klinik özelliklerine olumlu etki sağlar. Buna bağlı olarak materyalin polimerizasyon büzülmesinin daha $a z$, mekanik özelliklerinin daha yüksek olmasını ve kırılmaya dayanıklııılarının artmasını sağlar. Doldurucu boyutlarının küçük olması, rezinin optik özelliklerinide arttırır. Kompozit yüzeyinin pürüzsüz, aşınma direncinin yüksek ve yüzey parlaklığının daha iyi olmasını sağlar. ${ }^{3-5}$

Kompozit materyallerdeki gelişmelere rağmen özellikle yüksek strese maruz kalan bölgelerde ve tüberkülleri de içine alan arka diş restorasyonlarında, kırılma ve eğme direncine dayanıklılıklarının yeterli olmaması nedeni ile kullanımlarının kısıtlı olduğu bildirilmiştir. ${ }^{1,2} \mathrm{Bu}$ nedenle kompozit materyallerin fiberle-güçlendirilmesi gündeme gelmiştir. Fiberle güçlendirilmiş kompozitler (Fiber-reinforced composite; $F$ RC), kompozitlerin fiziksel özelliklerini arttırmayı amaçlayan ve fiber içeren rezin bazlı materyallerdir. ${ }^{6-12}$

Klinik dişhekimliğinde materyallerin fiberle güçlendirilmesi üzerine 1960 'lı yıllarda çalışmalar yapılmış ve akrilik rezinlerin güçlendirilmesi amacıyla cam fiberler kullanılmıştır. ${ }^{7-13}$ Fiberlerin esneklik, sertlik, basınca karşı direnç gibi mekanik özelliklerinin çok iyi olması, düşük özgül ağırlıkları, translüsensi, korozyona uğramamaları ve adeziv teknik ile bağlanma gösterebilmeleri gibi özellikleri, farklı alanlarda olduğu kadar kompozitlerin güçlendirilmesinde ve mekanik özelliklerinin iyileştirilmesinde kullanılmalarınaneden olmuştur. ${ }^{7,9-15}$ Fiberlerin bu güçlendirmedeki rolü, kırık stoperi şeklinde görev yaparak materyalin fiziksel özelliklerini arttırmaktır.Uygulanacak kuvvete bağlı olarak çeşitli fiberler üretilmektedir. ${ }^{7,9,16}$ Kompozitlerin güçlendirilmesinde örgü cam fiber veya kırpılmış olarak kompozitin içine katılmış fiberler kullanılmaktadır ${ }^{3,15}$. Fiberlerin güçlendirme kapasitesini;kullanılan fiber tipi, fiberin gelen kuvvetin yönüne göre yerleştirilmesi, restorasyondaki pozisyonu, fiberin ıslatılmış olması, içinde bulunduğu rezin matriksle adezyonu, materyaldeki fiber oranı etkiler. ${ }^{7,8,13,17-23}$ Günümüzde fiberle güçlendirilmiş kompozit rezinler yaygın olarak; periodontal splint, inley, onley gibi indirekt uygulamalar, protezlerin güçlendirilmesi ve tamiri, ön ve arka dişlere uygulanan sabit köprüler, implant üstü protez, endodontik post olarak ve pedodontide sabit yer tutucu yapımında kullanılmaktadır. ${ }^{7,8,14,17}$

İlk kez 1995 yılında dişhekimliğinde kullanılmak üzere üretilen akışkan kompozitler; hibrit yapıda, düşük viskoziteli, akıcı kıvamlı ve ışıkla sertleşen kompozitlerdir. Adeziv restorasyonlara uygun olarak hazırlanan kavitelerde, polimerizasyon büzülmesini engellemek ve stres kırıcı bir tabaka oluşturmak amacıyla geliştirilmişlerdir.Bu amaçla, kompozit rezin restorasyonların altında ince bir tabaka halinde uygulanması önerilmektedir. ${ }^{24-27}$ Posterior kompozitlerin yerleştirilmesinden önce kaviteye akıcı kompozit tabaka uygulanmasının, kavite duvarlarına daha iyi bir adaptasyon sağlayacağı rapor edilmiştir. ${ }^{26,27}$

Bu çalışmanın amacı, bir nanofil kompozit rezin materyalinin, cam fiber ile güçlendirilmesinin eğme direncine olan etkisinin araştırılarak, seçilmiş bazı örneklerin taramalı elektron mikroskobu ile incelenmesidir.

\section{MATERYAL VE METOD}

Fiberle güçlendirilmiş kompozitlerin eğme kuvvetleri karşısındaki dayanıklıığının incelenmesi amacıyla ISO 4049 standartlarına uygunn ${ }^{28}$, kalınlığı 2 mm, genişliği $2 \mathrm{~mm}$ ve uzunluğu $25 \mathrm{~mm}$ boyutlarında eşkenar dörtgen şeklinde metal bir kalıp hazırlandı (Resim 1). Bu kalıplardan hazırlanan ve her bir grupta 15 adet olmak üzere toplam 60 örnek aşağıda belirtilen dört çalışma grubuna ayrıldı;

I. Grup: Akışkan Kompozit (Filtek Flow) + Nanofil Kompozit (Filtek Supreme),

II. Grup: Nanofil Kompozit (Kontrol),

III. Grup: Akışkan Kompozit + Örgü Cam Fiber (EverStick Net) + Nanofil Kompozit, 
IV. Grup: Örgü Cam Fiber + Nanofil Kompozit.

Çalışmada kullanılan materyaller Tablo 1 de verilmiştir. Her test grubuna aşağıdaki işlem basamakları uygulandı:

Tablo 1. Çalışmada kullanılan materyaller

\begin{tabular}{|c|c|c|c|}
\hline Materyal & $\begin{array}{l}\text { Organik } \\
\text { Matriks }\end{array}$ & $\begin{array}{l}\text { Doldurucu içeriğ } \\
\text { büyüklüğü }\end{array}$ & Üretici firma \\
\hline $\begin{array}{l}\text { Filtek Flow } \\
\text { (Akıcı } \\
\text { kompozit) } \\
\end{array}$ & $\begin{array}{l}\text { Bis-GMA, } \\
\text { TEGMA }\end{array}$ & $\begin{array}{l}\text { Silika/zirkonya, } \\
\% 47, \text { Ort } 1.5 \mu \mathrm{m}\end{array}$ & $\begin{array}{l}\text { 3M ESPE, } \\
\text { Amerika Birleşik } \\
\text { Devleti }\end{array}$ \\
\hline $\begin{array}{l}\text { Filtek } \\
\text { Supreme } \\
\text { (Nanofil } \\
\text { kompozit) }\end{array}$ & $\begin{array}{l}\text { Bis-GMA, } \\
\text { TEGDMA, } \\
\text { UDMA, } \\
\text { Bis-EMA*, }\end{array}$ & $\begin{array}{l}\text { Silika zirkonya } \\
\text { nanoöbekler, \%78.5 } \\
20-60 \text { nm }\end{array}$ & $\begin{array}{l}\text { 3M ESPE, } \\
\text { Amerika Birleşik } \\
\text { Devleti }\end{array}$ \\
\hline $\begin{array}{l}\text { EverstickNet } \\
\text { (Önceden } \\
\text { Islatılmış } \\
\text { örgü } \\
\text { formunda } \\
\text { fiber) }\end{array}$ & $\begin{array}{l}\text { PMMA, } \\
\text { Bis-GMA }\end{array}$ & $\begin{array}{l}\text { Önceden silanlanmış } \\
\text { E-cam fiber, \%35 } \\
\mathrm{SiO}_{2}, \% 22 \mathrm{CaO}, \\
\% 15 \mathrm{Al}_{2} \mathrm{O}_{3}, \% 6 \\
\mathrm{~B}_{2} \mathrm{O}_{3}, \mathrm{az} \text { oranda } \\
\text { metal oksitler,Bis- } \\
\mathrm{GMA}, \text { PMMA }\end{array}$ & $\begin{array}{l}\text { StickTech,Turku, } \\
\text { Finlandiya }\end{array}$ \\
\hline $\begin{array}{l}\text { Adper Single } \\
\text { Bond } \\
\text { (Adeziv } \\
\text { sistem) } \\
\end{array}$ & $\begin{array}{l}\text { Bis-GMA, } \\
\text { etanol } \\
\text { HEMA, } \\
\text { su }\end{array}$ & $\begin{array}{l}\text { Silika } \\
\text { doldurucular } \\
\% 10,5 \mathrm{~nm}\end{array}$ & $\begin{array}{l}\text { 3M ESPE, } \\
\text { Amerika } \\
\text { Birleşik } \\
\text { Devleti }\end{array}$ \\
\hline
\end{tabular}

I. Grup: Düz bir zemin üzerinde ve yere paralel olan lamın üzerine yerleştirilen metal kalıbın $25 \mathrm{~mm}$ uzunluğundaki boşluğunun tabanına şeffaf bant (Mylar strip) kondu. Metal kalıbın boşluğuna ince bir tabaka akıı kompozit uygulanıp 20 saniye LED ışık cihazı ile polimerize edildi. Nanofil Kompozit tek seferde kalıbın içine konarak üzerine tekrar şeffaf bant ve lam yerleştirildi ve üzerine hafifçe bastııılı. Fazlalıklar alındıktan sonra lamın üzerinden ve kalıbın iki kenar ve orta kısmı olmak üzere üç bölgesinden 20 şer saniye ışık uygulandı. Daha sonra lam kaldırılarak aynı bölgelere tekrar 20 şer saniye ışık uygulaması (toplam 120 saniye) yapıldı.

II. Grup: Yukarıda belirtilen işlemler akıcı kompozit olmaksızın aynen uygulandı (Kontrol).

III. Grup: Grup 1 deki gibi yerleştirilen metal kalıbın içerisine ince bir tabaka akıcı kompozit uygulandı ve ışık uygulanmadı. Önceden doyurulmuş örgü cam fiber, hazırlanan kalıba uygun olarak (25 $\mathrm{mm} \times 2 \mathrm{~mm}$ ) özel bir makas yardımıyla kesildi. Fiber, özel bir spatül ile dikkatli bir şekilde, örneğin en alt kısmına yerleştirilip akıcı kompozitle birlikte 20 saniye polimerize edildi(Resim 2). Nanofil kompozit, tek seferde kalıbın içine konarak üzerine şeffaf bant ve lam yerleştirildi. Hafifçe lamın üzerine bastıııldı. Kompozitin fazlalıkları alındıktan sonra camın üzerinden ve örneğin her üçte birlik kısmından 20 şer saniye ışıkuygulandı. Lam kaldırıı aynı bölgelere tekrar 20 şer saniye ışıkuygulandı (toplam 120 saniye).

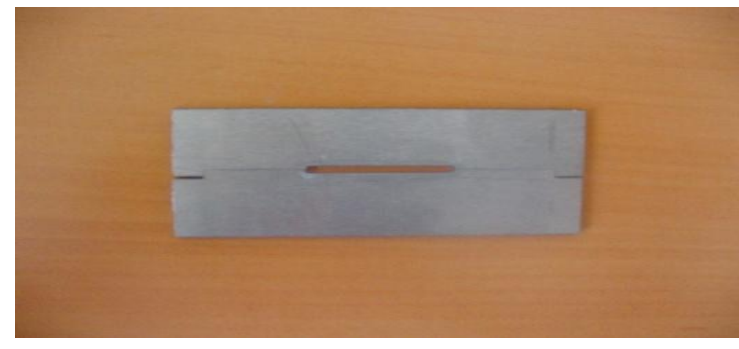

Resim 1. İki parçadan oluşmuş metal kalıp

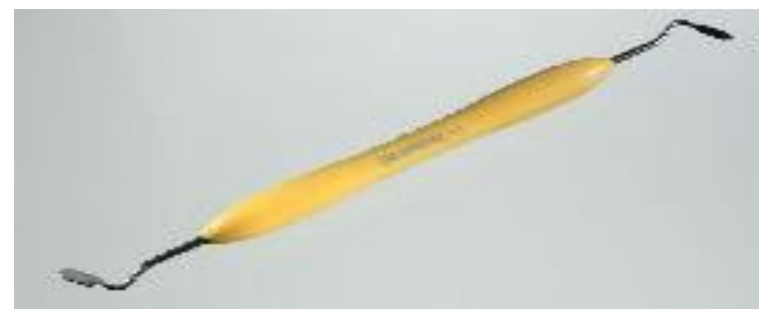

Resim 2. Fiberin yerleştirilmesinde kullanılan özel spatül

IV. Grup: Metal kalıba uygun kesilerek hazırlanmış olan önceden ıslatılmış örgü cam fiber, Mylar strip'in üzerine akıcı kompozit uygulanmadan direkt olarak yerleştirildi. Üzerine kompozit rezin tek tabaka halinde uygulandı. Mylar strip ve lam uygulaması diğer gruplardaki gibi yapıldı.

Renk faktörünün sabit tutulması amacıyla çalş̧mada Vita skalasına göre A3 rengi $\left(V{ }^{T}{ }^{T M}\right.$ Lumin Shade Guide, Vita Zahnfabric) kullanıldı. Tüm örneklerin polimerizasyonu, dalga boyu $470 \mathrm{~nm}$ ve gücü 400 $\mathrm{mW} / \mathrm{cm}^{2}$ olan LED ışık cihazı (Elipar Freelight, 3M ESPE, USA) ile sağlandı. Örnekler (toplam 60 adet) kalıptan çıkartıldıktan ve 24 saat $37^{\circ} \mathrm{C}$ de distile suda bekletildikten sonra üç nokta eğme testine tabi tutuldu. Test öncesinde her bir örneğin kalınlık ve genişliği dijital mikrometre ile ölçüldü (Digimatic, Mitutoyo Corp, Japan). Destekler arası mesafe $20 \mathrm{~mm}$ olarak belirlendi (ISO 4049). Üç nokta eğme testi Dokuz Eylül Üniversitesi Mühendislik Fakültesi, Metalurji ve Malzeme Mühendisliği Bölümü Laboratuvarında ve Universal Test Cihazı (AG- 50 kNG, Shimadzu, Japan) kullanılarak gerçekleştirildi. Teste başlamadan önce

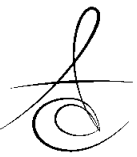


paslanmaz çelikten hazırlanmış olan alt yapı, Universal test cihazına yerleştirildi.

Universal Test Cihazına, kırımayı gerçekleştirecek olan kırıcı uç bağlandı. Önceden dijital mikrometre ile orta noktası tespit edilmiş olan örneklerin, tam ortasına $90^{\circ}$ gelecek şekilde (Resim 6) Universal test cihazı $1 \mathrm{~mm} /$ dakika hızla çalıştırılarak örneklere kuvvet uygulandı. Örnekte kırılma olduğunda cihaz dururuldu. Örneklerde kırılmaya neden olan maksimum kuvvet değerleri belirlendi. Örneklerin eğme dayanımları 3FL / $\mathbf{2 b d}^{\mathbf{2}}$ formülüne göre hesaplandı ( $F$ =uygulanan kuvvet, $\mathrm{L}=$ destekler arası mesafe, $\mathrm{b}=$ örneğin eni, $d$ = örneğin kalınlığı).

\section{Örneklerin taramalı elektron mikroskobu} (SEM) ile değerlendirilmesi

Üç nokta eğme testinde elde edilen ortalama değerlere en yakın değeri gösteren her gruptan üç örneğin (toplam 12 adet) kırılma yüzeyi, taramalı elektron mikroskobunda (SEM) incelendi (Jeol JSM 6060, Japan). SEM incelemesi Dokuz Eylül Üniversitesi Mühendislik Fakültesi Metalurji ve Malzeme Mühendisliği Bölümünde yapıldı.

Bulguların istatistiksel olarak değerlendirilmesi Ege Üniversitesi Fen Fakültesi Bioistatistik Bölümünde gerçekleştirildi. Fiberle güçlendirilmiş kompozitlerin eğme direnci Kruskall Wallis ve gruplar arasındaki farklılık Mann Whitney U testi kullanılarak belirlendi.

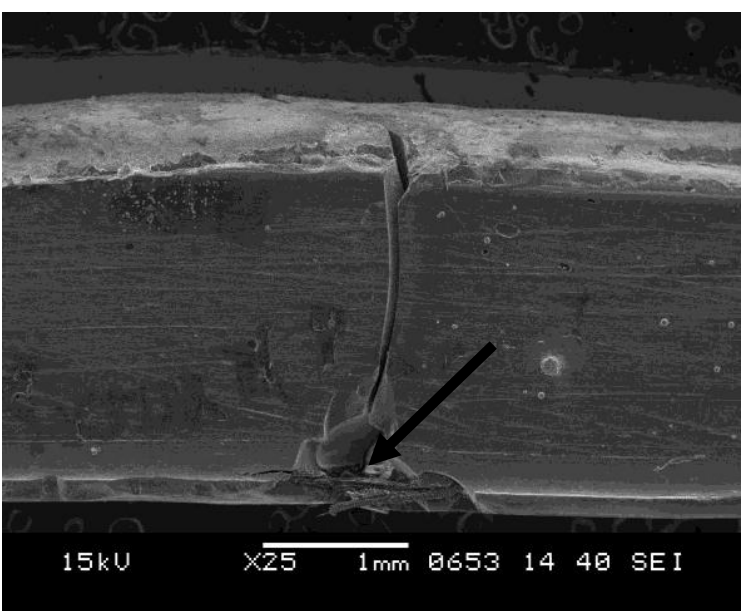

Resim3 a. Fiberle güçlendirilmiş kompozit örnekte (Gr. III) meydana gelen kırık hattının SEM görüntüsü $(\rightarrow \rightarrow$. Hattınfiber tabakasında sınırlı kaldığı gözlenmektedir (X25)

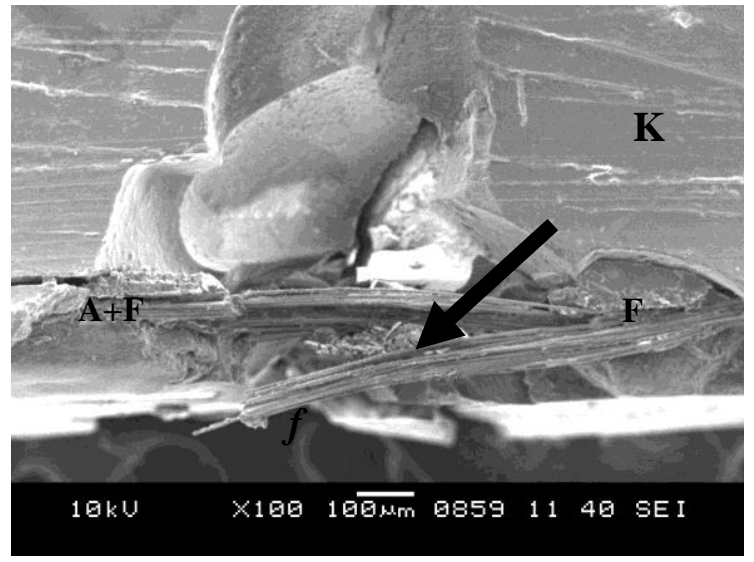

Resim 3 b. Resim 1-a'da ok ile gösterilen kısmın X100 büyütmedeki görüntüsü (K. Kompozit, $F$. Fiber, A+F. Akıcı kompozit ve $f$. fiberde kopma görülen bölge)

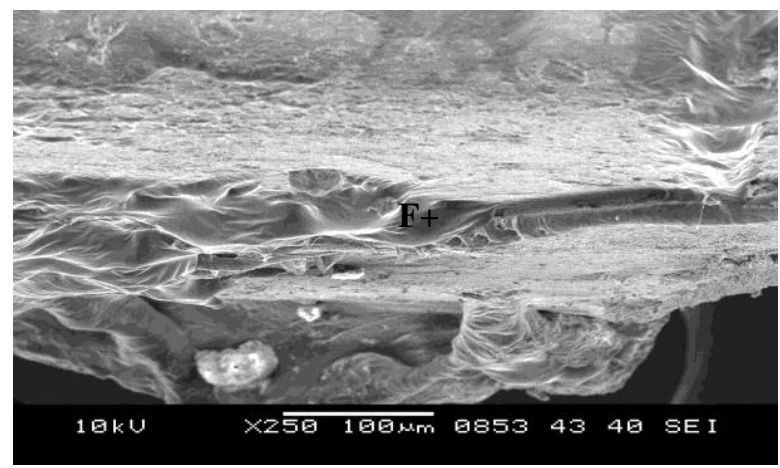

Resim 4. Kompozitin fiberle iyi bir şekilde bütünlük sağladığını gösteren SEM görüntüsü (F.Fiber, K.Kompozit) (X250)

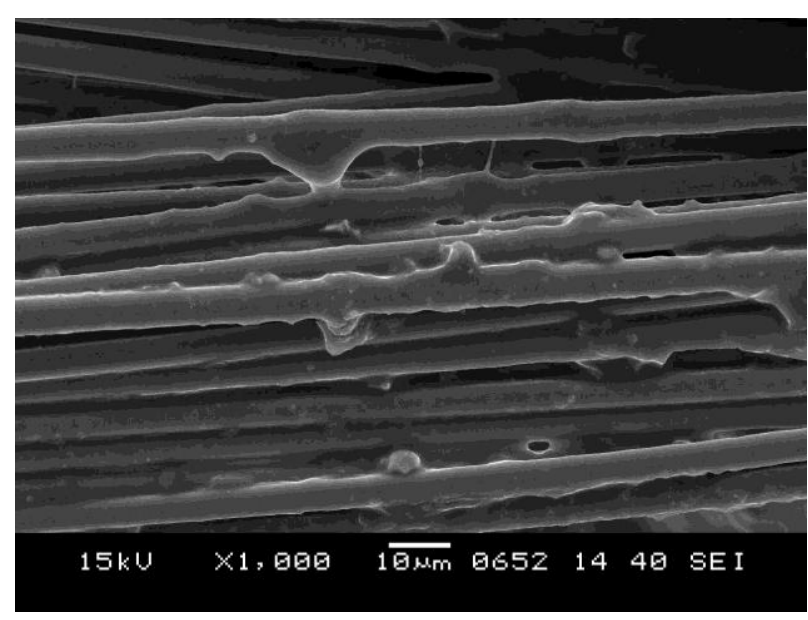

Resim 5. Grup III'e ait bir örnekte, fiber lifleri içine infiltre olmuş akıcı kompozitin SEM'deki görüntüsü (X1000) 


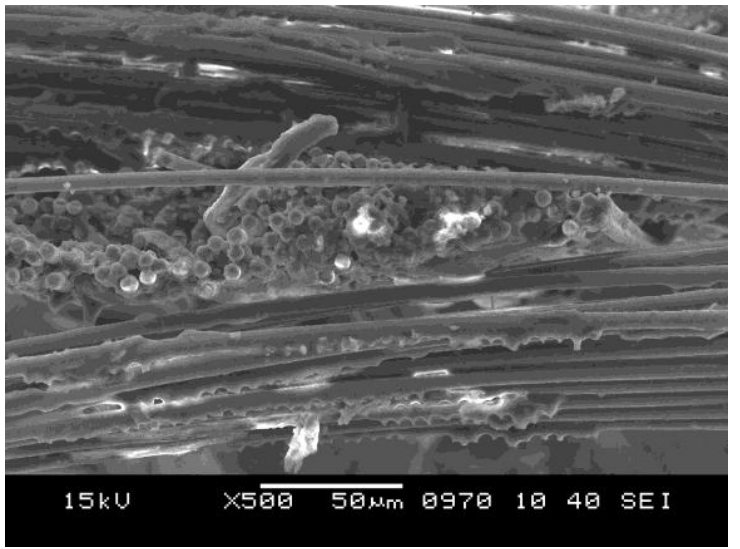

Resim 6. Grup III'e ait bir örnekte, fiber liflerinin farklı yönlerdeki konumunu gösteren SEM görüntüsü (X500)

\section{BULGULAR}

Fiberle güçlendirmenin nanofil kompozitin eğme direncine etkisinin karşılaştırmalı olarak incelendiği çalışmada, üç nokta eğme testi sonucunda Grup I, II, III, IV'ün eğilme direnci değerlerinin ortalama ve standart sapmaları sırasıyla; 93.6 $\pm 4,85.5 \pm 6,107 \pm 9$ ve $101 \pm 5 \mathrm{MPa}$ olarak belirlendi.

Elde edilen en yüksek eğme direnci değeri akışkan kompozit materyali ile beraber fiber uygulanan kompozit rezin grubunda gözlenirken, sadece kompozit grubunun (Kontrol) en düşük değere sahip olduğu tespit edildi. Kontrol grubunun, gerek fiber ile güçlendirilmiş kompozit gerekse akışkan ile beraber uygulanan kompozit grubuna göre eğilme direnç değerleri açısından aralarında istatistiksel olarak anlamlı bir fark olduğu belirlendi $(p<0.05)$. Çalışmada ayrıca nanofil kompozitin fiberle uygulanmasının, tek başına veya akıcı kompozitle uygulanmasından daha yüksek eğme direnci değerleri gösterdiği saptandı. Akışkan kompozit uygulanmasının, kompozit materyalin eğilme direncini, akışkan uygulanmayan kompozit grubuna göre anlamlı bir şekilde arttırdığı gözlendi $(p<0.05)$.

Kırılma meydana gelen örnekler SEM ile incelendiğinde, akışkan kompozit materyali ile beraber fiber uygulanan kompozit rezin grubunda meydana gelen kırılmanın, gerilim bölgesine yerleştirilen fiberle sınırlı kaldığı ve uygulanan cam fiberin, kırık stoperi olarak işlev yaptığı, meydana gelen stresin fiberler tarafından karşılandığı ve kırılan parçaların birbirlerinden ayrılmasını engellediği saptandı (Resim $3 a, b)$. Yine SEM incelemelerinde akıc kompozitin, fiberle iyi bir şekilde bütünlük sağladığı gözlendi (Resim 4, 5, 6).

\section{TARTIŞMA}

Kompozit rezin materyallerin özellikle arka grup dişlerin restorasyonlarında klinik başarısızlıklarının başında dolgu ve kenarlarında meydana gelen kırılmalar olduğu belirtilmiştir ${ }^{1}$. Bu nedenle materyaller devamlı geliştirilmektedir. Bir restoratif materyalin klinik başarısı, fiziksel ve mekanik özellikleri ile doğrudan ilgilidir. Materyalin klinik başarısını belirleyen eğme, basma, elastisite ve sertlik olarak tanımlanan mekanik özelliklerini tespit etmek için mekanik testlerden yararlanılmaktadır. ${ }^{28-32}$ ISO (International Organization for Standardization) standartları, materyalin fiziksel ve mekanik özelliklerini belirlemek için standart test tekniği olarak kabul edilmiştir. Çalışmamızda gruplara ait eğme direnci değerlerinin saptanmasında ISO 4049 standartlarına uygun olarak üç nokta eğme testi uygulandı.

Yapılan çalışmalarda, düşük eğilme direncinin restorasyonlarda fraktürlerin daha sık gözlenmesine neden olduğu,restoratif materyallerin çiğneme kuvvetlerine dayanabilmesi için eğilme direncinin $50 \mathrm{MPa}$ 'dan az olmaması gerektiği rapor edilmiştir. ${ }^{29}$ Çalışmamızda eğilme direnci değerleri; sadece kompozit uygulandı-

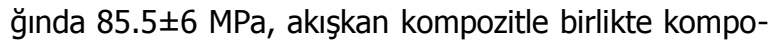
zit uygulandığında $93.6 \pm 4 \mathrm{MPa}$, alt yapı olarak fiber uygulanan grupta $107 \pm 9 \mathrm{MPa}$ ve akıc kompozit kullanılmadan uygulanan fiber grubunda ise $101 \pm 5$ MPa olarak saptandı. Bu şekilde tüm gruplarda eğme direnci değerlerinin istenilen değerlerin üzerinde ve en yüksek değerlerin ise fiberle uygulanmış kompozit rezin grubunda olduğu belirlendi $(p<0.05)$.

Kullanılan restoratif materyalin matriks yapısı içerisinde yer alan doldurucu oranı ile materyalin mekanik özellikleri arasında pozitif bir ilişki olduğu belirtilmiştir. ${ }^{1,2}$ Bu nedenle klinik çalışmalarda seçilecek olan restoratif materyalin yüksek doldurucu içeriğine sahip olması istenilen bir özelliktir. Buna ek olarak kullanılan kompozitin yapısındaki doldurucuların partikül boyutlarının da eğilme direncinde önemli olduğu çeşitli araştırıcılar tarafından bildirilmiştir. ${ }^{2,5} \mathrm{Bu}$ çalışmada ağırık olarak \% 78.5 oranında silika-zirkonya doldurucu içeriğine sahip, 5-20 nm boyutunda nanoöbek ve $20-75 \mathrm{~nm}$ boyutunda nanodoldurucu içeren nanofil kompozit (Filtek Supreme) kullanıldı.

Restoratif materyallerin mekanik testlerinde örnek boyutlarının ve test yönteminin standardizasyonu kadar, yükleme hızı da önemle üzerinde durulan

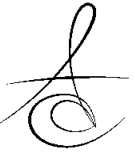


bir konudur. Yükleme hızı arttıkça, materyalin kırılması için yeterli süre oluşmadığından hatalı sonuçlar alınabilmektedir. ${ }^{30}$ Çalışmamızda ISO standartlarına uygun şekilde yükleme hızı olarak $1 \mathrm{~mm} / \mathrm{dk}$ uygulandı. $\mathrm{Bu}$ şekilde daha önceden yapılan çalışmalarla karşılaştırma yapma imkanı sağlanmış oldu.

Fiberle güçlendirilmiş dental materyallerin mekanik özelliklerinin belirlenmesinde fiberin tipinin ve yönünün, fiberlerin doyurulmasının, örnek boyutlarının, ortamın standardizasyonunun, örneklerin suda bekletilmesinin ve uygulanan yükleme hızının önemli olduğu çeşitli araştırmalarda belirtilmiştir. ${ }^{7-14,22}$

Çalışmamızda; kompozitin güçlendirilmesi amacı ile, tüm yönde kompozit yapıyı güçlendirmesi ve kuvvet yönünün tahmin edilemediği durumlarda uygulanması, diğer fiber tiplerine göre üstün mekanik özelliklere sahip olması, ayrıca etrafında bulunan BisGMA ve PMMA tabakası nedeniyle kompozit rezinle arasındaki adezyonunun iyi olması nedenleriyle örgü formunda (önceden ıslatılmış) cam fiber kullanıldı. Bunların yanında, önceden emdirilmiş fiberlerin hekimin uygulayacağı basamakları elimine etmesi, önceden doyurulmamış fiberlere göre daha yüksek fiber içermesi ve buna bağlı olarak daha yüksek eğilme direncine sahip olması gibi nedenlerden dolayı örgü cam fiber tercih edildi.

Ellakwa ve arkadaşları, ${ }^{22}$ fiberle güçlendirilmiş kompozitineğilme direncinin, fiber içermeyen kontrol grubuna göre, ortalama anlamlı derecede yüksek olduğunu saptamışlardır. Aynı araştırıcılar, inceledikleri üç farklı fiber tipinde en yüksek eğilme direncinin cam fiberle güçlendirilmiş kompozitte elde edildiğini, polietilen ve aramid fiberlerin ise birbirlerine benzer eğilme direncine sahip olduğunu, ayrıca fiberin önceden doyurulmasının materyalin eğilme direncini arttırdığını bildirmişlerdir.

Bae ve arkadaşları ${ }^{32}$ polietilen, poliaramid ve üç farklı cam fiber (FibreKor, Glasspan, Vectris) ilave edilerek hazırladıkları kompozit rezin örneklere uygulanan üç nokta eğme testi sonucunda, fiber ilave edilmesinin tüm örneklerin eğilme direncini anlamlı şekilde arttırdığını saptamışlardır. Ayrıca poliaramid ve cam fiberlerin, polietilen fibere göre daha yüksek bir eğilme direncine sahip olduğunu tespit etmişlerdir. Çalışmamızın bulguları, fiberlerin kompozitin eğilme direncini anlamlı bir şekilde arttırdığını bildiren çalışmalarla paralellik göstermektedir. ${ }^{22,31,32}$
Fiberin, eğme testi uygulanacak örneğin hangi bölgesine yerleştirilmesi gerektiği de çalışmaların ilgi odağını oluşturmuştur. Chung ve arkadaşları ${ }^{31}$ geçici sabit parsiyel protez yapımında kullanılan akrilik kaide materyaline cam fiber ilavesinin eğilme dayanıklılı̆ına etkisini inceledikleri çalışmalarında, tek yönlü fiberleri dört farklı lokalizasyonda yerleştirmişler vehazırlanan kalıpların1/3 alt kısmına yerleştirilen örneklerin diğer gruplara göre anlamlı bir şekilde daha yüksek dirence sahip olduğunu belirtmişlerdir.

Kanie ve arkadaşlar ${ }^{14}$, akrilik rezin materyale ilave edilenörgü formundaki cam fiberin lokalizasyonunun, materyalin eğilme direncini etkilediğini, fiberin çekme gerilimlerinin oluştuğu kısma yerleştirilmesi ile en yüksek eğilme direnci ve elastisite modülü saptandığını, fiber ilavesinin materyalin eğilme direncini anlamlı olarak arttırdığını belirtmişlerdir.

Benzer şekilde Lassila ve Vallittu ${ }^{21}$ kompozitin basma kuvvetlerinin oluştuğu üst, çekme gerilimlerin oluştuğu alt ve kompozit tabakalarının arasına fiber uygulandığında, en yüksek eğilme direncinin, çekme gerilimlerinin oluştuğu kısıma yerleştirilmesiyle elde edildiğini tespit etmişlerdir. Çalışmamızda yukarıda belirtilen çalışmalar göz önüne alınarak, örgü formundaki cam fiber, daha yüksek eğilme direnci saptandığı bildirilen çekme gerilimlerinin oluştuğu kalıbın alt kısmına yerleştirilerek üzerine kompozit materyali uygulandı. Cam fiberle güçlendirmenin, nanofil kompozitin eğme direncini arttırdığı şeklindeki bulgumuzun, daha önce yapılmış çalışmalarda ${ }^{22,32}$ alınan başarılı sonuçlarla uyum içinde olduğu gözlendi.

\section{SONUÇ}

Bu çalışmanın sonucunda; a) Nanofil kompozit rezinin altına akışkan kompozitle birlikte örgü cam fiber tabakası uygulanmasının, kompozitin eğme direncini anlamlı şekilde arttırdığı $(p<0.05)$.

b) Eğme testi sonrasında yapılan SEM incelemesinde, fiberle güçlendirilmiş kompozit örneklerde meydana gelen kırımanın, gerilim bölgesine yerleştirilen fiberle sınırlı kaldığı ve kırılma bölgesinin dışında kırığın ilerlemediği, sadece kompozit uygulanan örneklerde ise kırığın gerilim bölgesini de içine aldığı saptandı.

Fiberle güçlendirilmiş nanofil kompozitlerin ağızda yüksek çiğneme basıncına maruz kalan bölgelerde başarı ile kullanılabileceği fikrine varıldı. 


\section{KAYNAKLAR}

1. Manhart J, Chen HY, Hamm G, Hickel R. Review of the Survival of Direct and Indirect Restorations In Posterior Teeth of the Permanent Dentition. Operative Dentistry 2004; 29:481-508.

2. Ferracane JL. Resin Composite-State of the Art. Dental Materials 2011; 27: 29-38.

3. Beun S, Glorieux T, Devaux J, Vreven J, Leloup G. Characterization of Nanofilled Compared to Universal and Microfilled Composites. Dental Materials 2007; 23: 51-9.

4. Mitra SB, Wu D, Holmes HB. An Application of Nanotechnology in Advanced Dental Materials. Journal of American Dental Association 2003; 134 : 1382-90.

5. Chen MH. Update on Dental Nanocomposites. J Dent Res 2010; 89: 549-60.

6. Butterworth, C., Ellakwa, A.E, Shortall, A. FibreReinforced Composites in Restorative Dentistry. Dent Update 2003; 30:300-8.

7. Freilich MA, Meiers JC, Duncan JP, Goldberg AJ. Fiber-Reinforced Composites in Clinical Dentistry. Chicago, Berlin, London, Tokyo; Quintessence Publishing Co, Inc: 2000. p. 9-22.

8. Aydın C, Yılmaz H, Korkmaz T, Atlı Y,Zan T. Değişik Kron Köprü Veneer Materyallerinin Sertliklerinin İncelenmesi. Cumhuriyet Üniv Diş Hek Fak Derg 1998;12:46-53.

9. Yılmaz $H$, Aydın C. Akrilik Rezinlerin Güçlendirme Teknikleri. Atatürk Üniv Diş Hek Fak Derg 2002;12:46-53.

10.Garoushi S, Lippo VJ, Tezvergil A, Vallittu PK. Load Bearing Capacity of Fiber-Reinforced and Particulate Filler Composite Resin Combination. Journal of Dentistry 2006; 34:179-84.

11. Pereira, CL, Demarco FF, Cenci MS, Osinaga PWR, Piovesan EM. Flexural Strength of Composites: Influence of Polyethylene Fiber Reinforcement and Type of Composite, Clin Oral Invest 2003;7:116-9.

12. Freilich MA, Karmaker AC, Burstone CJ, Goldberg AJ. Development and Clinical Applications of a Light- Polymerized Fiber-Reinforced Composite. J Prosthet Dent 1998; 80:311-8.

13.Xu HHK, Quinn JB, Smith DT, Guiseppetti AA. Effect of Different Whiskers On The Reinforcement of Dental Resin Composites. Dent Mater 2003; 19:359-67.
14. Kanie T, Arikawa H, Fuji K, Ban S. Mechanical Properties of Reinforced Denture Base Resin: The Effect of Position and The Number of Woven Glass Fibers. Dent Mater J 2002;21:261-9.

15. Van Dijken JWV, Sunnegardh-Grönberg K. FiberReinforced Packable Resin Composites in Class II Cavities. Journal of Dentistry 2006;34: 763-9.

16.Goldberg, AJ. Freilich MA.. An Innovative PreImpregnated Glass Fiber For Reinforcing Composites. Dent Clin North Am 1999;43:127-33.

17. Freilich MA, Karmaker AC, Burstone CJ, Goldberg AJ. Development and Clinical Applications of $A$ Light-Polymerized Fiber-Reinforced Composite. J Prosthet Dent 1998;80:311-8.

18. Fennis WMM, Tezvergil A, Kuijs RH, Lassila LVJ, Kreulen CM, Creugers $\mathrm{NHJ}$, Valittu PK. In Vitro Fracture Resistance of Fiber Reinforced CuspReplacing Composite Restorations. Dental Materials 2005;21:565-72.

19. Vallittu PK. Compositional and Weave Pattern Analyses of Glass Fibers in Dental Polymer Fiber Composites. J Prosthodont 1998 7:170-6.

20. Lastumaki TM, Lassila LV, Vallittu PK. The semiInterpenetrating Polymer Network Matrix of FiberReinforced composite and Its Effect on The Surface Adhesive Properties. J Mater Science Mater Med 2003;14:803-9.

21. Lassila LVJ, Vallittu PK. The Effect of Fiber Position and Polymerization Condition on The Flexural Properties Of Fiber-Reinforced Composites. J Contemp Dent Pract 2004;5:14-26.

22. Ellakwa $A E$, Shortall $A C$, Marquis PM. Influence of Fibre Type and Wetting Agent on The Flexural Properties of An Indirect Fibre-Reinforced Composite. J Prosthet Dent 2002;88:485-90.

23. Dyer S, Lassila LV, Jokinen M, Valittu PK. Effect of Fiber Position and Orientation on Fracture Load of Fiber-Reinforced Composite. Dent Mater 2004;20: 947-55.

24. Chen Stefanski S, Van Dijken JWV. Clinical Performance of A Nanofilled Resin Composite With and Without an Intermediary Layer of Flowable Composite: A 2- Year Evaluation. Clinical Oral Investigations 2010; 10:119-25. 
25. Efes BG, Dörter C, Gömeç Y, Koray F. Two Year Clinical Evaluation of Ormocer and Nanofill Composite With and Without a Flowable Liner. Journal of Adhesive Dentistry 2006;8 119-26.

26. Unterbrink GL, Liebenberg WH. The Effect of Flowable Resin Composite on Microleakage and Internal Voids in Class II Composite Restorations. Operative Dentistry 2004; 29:713-9.

27. Ernst CP, Canbek K, Aksogan K, Willerhausen B. Two Year Clinical Performance of Packable Posterior Composite With and Without a Flowable Composite Liner. Clinical Oral Investigations 2003; 7:129-34.

28. International Standardization Organization (ISO) Dentistry- Resin-Based Filling Materials. Geneva: (2 nd ed.) ISO 4049. 1988.p. 6-8.

29. Chung SM, Yap AUJ, Chandra SP, Lim CT. Flexural Strength of Dental Composite Restoratives: Comparison of Biaxial and Three-Point Bending Test. J Biomed Mater Res 2004; 71:278-83.

30. Attar N, Çiftçi Y. A Comparison of the Flexural Strength and Elastic Modulus of Condensable and Hybrid Composite Resins. Hacettepe Diş Hek Fak Derg 2006;30:42-50.

31.Chung $K$, Lin T, Wang F. Flexural Strength of a Provisional Resin Material with Fibre Addition. J Oral Rehabil 1998;25:214-7.

32. Bae JM, Kim M, Hattori M, Hasegawa K, Yoshinari M, Kawada E. The Flexural Properties of FiberReinforced Composites With Light-Polymerized Matrix Int J Prosthod 2001;14: 33-9.

\author{
Yazışma Adresi: \\ Dr. Ümit CANDAN \\ İzmir Eğitim Diş Hastanesi, \\ Sümer Mah. 451 Sk. Konak/İzmir \\ TIf: 05324230047 \\ E- Mail: ucandan@hotmail.com
}

